\title{
Relationship between Reading Comprehension and Vocabulary Knowledge in English Authentic Text among Afghan English as Foreign Language Learners
}

\author{
Muhammad Sharif Hasanzoy*, Zahidullah Abid \\ Faculty of Education, Kunduz University, Afghanistan
}

Received January 22, 2021; Revised September 14, 2021; Accepted October 17, 2021

\section{Cite This Paper in the following Citation Styles}

(a): [1] Muhammad Sharif Hasanzoy, Zahidullah Abid, "Relationship between Reading Comprehension and Vocabulary Knowledge in English Authentic Text among Afghan English as Foreign Language Learners," Linguistics and Literature Studies, Vol. 9, No. 4, pp. 102 - 109, 2021. DOI: 10.13189/lls.2021.090402.

(b): Muhammad Sharif Hasanzoy, Zahidullah Abid (2021). Relationship between Reading Comprehension and Vocabulary Knowledge in English Authentic Text among Afghan English as Foreign Language Learners. Linguistics and Literature Studies, 9(4), 102 - 109. DOI: 10.13189/lls.2021.090402.

Copyright $\bigcirc 2021$ by authors, all rights reserved. Authors agree that this article remains permanently open access under the terms of the Creative Commons Attribution License 4.0 International License

\begin{abstract}
There have been few researches in Afghanistan that have looked into the relationship between reading comprehension and vocabulary knowledge among EFL learners. As a result, the goal of this study is to investigate the relationship between reading comprehension and vocabulary knowledge in actual English texts among Afghan students studying English as a Foreign Language (EFL). This research is based on quantitative correlation design. The questionnaire and actual text were utilized to collect data in the study, which were based on Laufer and Sim's (1998) reading and vocabulary testing methodologies. All respondents in this study consisted of forty $(n=40)$ Afghan EFL students from Kunduz University, ten females and thirty males. The data were analyzed using descriptive analysis and inferential tests in Statistical Software Package (SPSS) Version 24. (Pearson correlation). It is hoped that this study would raise awareness among Afghan EFL instructors about the need to revise their syllabus, particularly in regards to reading courses, in order to deliver effective teaching to their EFL students. More research on university and school EFL students can be performed to gain more reliable and in-depth data about reading comprehension and vocabulary knowledge.
\end{abstract}

Keywords Reading Comprehensions, Vocabulary Knowledge, Authentic Text, English as a Foreign Language Learner

\section{Introduction}

English is an international language that is widely used in daily communication, as well as for Academic Purposes (English for Academic Purposes - EAP) and Specific Purposes (English for Specific Purposes - ESP) (English for Specific Purposes - ESP).). English as a second/foreign language is weaved from several threads, such as teachers with different personalities, students, the situation, and the relevant languages spoken by learners and teachers [1]. Apart from the four primary strands, there is another important strand that incorporates the four fundamental skills that make up a language. They are reading, writing, listening and speaking and in order to acquire the target language, learners must practice them frequently. Reading, writing, listening, and speaking are just a few of the essential English abilities that students must practice on a regular basis in order to acquire. Learners must practice both the sub-skills of language acquisition and the primary components of language learning in order to master a language. Sub-skills, according to [2,] are the building blocks for the primary skills in the language learning process. As a result, practicing language sub-skills like grammar, vocabulary, and pronunciation can allow learners to utilize a language effectively and communicatively. Reading and listening, on the other hand, are receptive skills, whereas speaking and writing are productive attributes. One of the common themes that 
many scholars are interested in is the relationship between reading comprehension and vocabulary knowledge, which is the focus of this study. [3] noted that, despite the fact that the term "vocabulary knowledge" is diverse and has many dimensions, it is undeniably important in any reading comprehension job. As previously said, the relationship between vocabulary knowledge and reading comprehension is a wide-reaching research topic, as evidenced by [4], which claims that both L1 and L2 experience a correlation between word knowledge and text understanding. As a consequence, there is a link between vocabulary as a sub-skill and reading as a main skill. Similarly, plenty of other research have found that language learners improve their vocabulary knowledge by accident as a result of intensive reading. This is backed by [5], who conducted a research at Saudi Arabia's King Abdulaziz University to see if students may learn collocations by being exposed to target text repeatedly. The quantitative study revealed the chosen respondents memorize the collocations by reading extensively. They go on to state that understanding the importance of vocabulary knowledge is especially crucial in second language education, where reading is the primary focus, because it will facilitate instructors and course planners to align vocabulary goals and forming vocabulary syllabi. As this research is being undertaken in Afghanistan, it will provide insight into the English language situation, particularly at the secondary and tertiary levels. The current study's goal is to see if there's a link between reading comprehension and English vocabulary knowledge in actual texts among Afghan EFL students. The study's purpose leads to the following research question:

\section{Research Question:}

Does degree of reading comprehension and amount of vocabulary knowledge relate with each other in English authentic texts among Afghan EFL learners significantly?

\section{Hypothesis}

Null hypothesis

Degree of reading comprehension and amount of vocabulary knowledge does not relate with each other in English authentic texts significantly.

\section{Alternative hypothesis}

Degree of reading comprehension and amount of vocabulary knowledge relates with each other in English text among Afghan EFL learners.

\section{Literature Review}

Many academics have underlined the importance of vocabulary knowledge as one of the most crucial parts of language learning. As a conclusion, [2] claimed that having a larger vocabulary can assist learners in not just extracting the correct meaning from a situation, but also in communicatively applying that information in language learning and communication. Similarly, [6] contends that vocabulary knowledge is commonly recognized as a vital tool for second language learners since a lack of vocabulary knowledge in the L2 impedes successful communication. Moreover, many academics feel that while vocabulary knowledge facilitates language usage, language use lays the way for increased vocabulary knowledge. Listening to and writing with new words is recommended because it allows for retrieval as well as real recitation, which reinforces and builds vocabulary knowledge through the use of listening and reading texts and application in a variety of speaking and writing tasks [7-8]. Furthermore, according to [9], students who engaged with vocabulary through their employment, playing with the language in a situation where language exchanges were relevant, innovative, and unpredicted, had a larger vocabulary.

Afghans also speak a variety of languages, including Pashto, Dari, Tajiki, Uzbeki, Turkmani, Pashyaee, and Hazaragi. The majority of Pashtuns are able to acquire and speak other spoken languages, although other ethnic groups fail to learn Pashto. It's due to the Pashto language's linguistic peculiarities. In Afghanistan, English is taught as a foreign language. Afghanistan has a total population of 32 million, but only $6 \%$ of the Afghan population understands English. This is due to a lack of Internet access, a lack of quality English language instruction in general, a lack of time dedicated to English language teaching in primary, secondary, and tertiary schools, and a lack of access to quality English language instruction outside of provincial capitals where the level of instruction is higher and supported by private language instruction facilities.

They also have to study fourteen additional disciplines that are part of the Afghan Ministry of Education's curriculum. These courses are taught in Dari and Pashto, the Afghanistan's native languages, in all government and private schools [10]. As a result, English learning and teaching receives minimal attention in schools and universities, particularly in terms of strengthening the learner's reading and vocabulary skills. Also, pupils who live in the center of their province have access to high-quality education and private institutes to develop their English knowledge in Afghanistan, and they perform better in the English language than those who do not. [11]

As previously stated, vocabulary is the fifth and most important component of a language's set of often used terms. A helpful and vital tool for communication and obtaining new knowledge is a vocabulary that develops with age. [12] supports this view by stating that vocabulary is necessary when utilizing a language and is extremely important for every language student Importantly, it is one of the comprehensive constituents of language for speaking that is deprived of grammar, communication is occurred unremarkably. [13]. Furthermore, vocabulary can be 
considered a language's fifth skill, and it can be applied to any aspect of the target language, such as phonology, morphology, syntax, semantics, and so on. Furthermore, language instructors, students, materials writers, and researchers all concur that mastering a second language requires studying vocabulary [13].

Reading is one of the six key components of the English language (together with writing, hearing, speaking, vocabulary, and culture), and it is crucial for language learners in second language acquisition. Skimming and scanning are two reading procedures that are employed for distinct purposes and require this competence skimming, for example, is used to capture basic information about a text, whereas scanning is used to find specific information. This is confirmed by [14], who claims that children in primary school learn to read to construct meaning, locate main concepts, and scan for broad information as purposeful acts. They can perform the same behaviors with less effort and awareness after some experience. Scanning, on the other hand, is considered a speedy reading approach when someone scans with a question in mind [15]. They also recommended that scanning exercises can help people learn to skip through superfluous words so they can read faster. Reading researchers have been held to a higher standard than ever before in recent years in terms of putting theory and drill into practice. This is done to combine concept and learning activates with clear and effective models of reading enhancement, curriculum, instruction, and evaluation. According to [16], vocabulary knowledge can be thought as a "route" that directs readers to ideas. It means that lexical storage (vocabulary) is extremely important in language acquisition for communication and text comprehension. The study of [17] concludes that hearing and reading are the causes of vocabulary development, as mentioned in the study of [17]. This is especially true for students who are learning English as a second language and enrolling in English-medium colleges. Additionally, [7] argues that lexical information is often regarded like an essential tool for language students, and that a lack of vocabulary knowledge forms barriers for language students to speak properly. Because vocabulary is so important in a foreign language, especially, language instructors all over the world use a variety of methods to teach new terms in their classes. According to research in both first and second languages, vocabulary knowledge is one of the most reliable predictors of new facts and information for a reader. A common finding from different studies is that vocabulary knowledge and reading comprehension have a strong relationship. This viewpoint is shared by [19], who claims that language awareness and comprehension of printed information are inextricably linked and have a direct impact on one another. He also maintains that lexical information has always been the primary determinant of a passage's difficulty. [20] claims that "after reviewing the empirical evidence for each of the foregoing hypotheses, Alderson finds that reading in a second language is both a reading and a language problem."
[21] believes that reading increases academic performance in all disciplines, in addition to enhancing vocabulary and reading comprehension. Individuals who read enough have more consistent literacy abilities and a larger number of vocabularies, which is one of the determinants of reading comprehension. He also highlights the importance of reading to kids in many sections of the curriculum, quoting. This supported by [22], who believe that reading helps both in nurturing and developing the mind, as well as promotes academic ability. Their findings suggest that the key element driving individual differences in early learners' vocabularies is reading volume, not spoken communication. [23] suggest that if a language educator determines the number and kind of words pupils know, he or she may use several strategies to improve their vocabulary. According to them, if a student's lexical information is incomplete, teachers might choose to increase it so that it has a significant impact on the overall language performance. Limited vocabulary knowledge leads to poor reading comprehension and obstructs the educational study that is initially desired of students [23]. To put it another way, the goal of reading is comprehension, thus teachers must look for ways to expand the vocabulary of non-native English-speaking students, resulting in enhanced reading comprehension. [24] In reality, according to Boyer, the Common Core State Standards have resulted in an increase in text complexity as well as increased comprehension burdens.

Many researches have shown that students' word awareness and tacit knowledge can help learners improve their reading and comprehension [25]. According to the researcher, the more language knowledge students have, the more able they are to comprehend what they read. [26] shown that word information in reading has garnered a lot of attention these days in the area of L2 vocabulary and comprehension research. Similarly, despite the fact that most researchers and professionals agree that vocabulary knowledge has at least two dimensions: breadth (size) and depth (quality), the majority of study has focused on vocabulary breadth rather than vocabulary depth. The majority of scholars agree that reading makes language improvement easier [27]. This is backed by [26], who believes that the more reading students undertake, the greater their vocabulary knowledge will increase. Reading can also assist pupils improve their spelling and writing abilities [26]. Furthermore, the author says that understanding how vocabulary knowledge aids reading comprehension would be an important subject to investigate because it may provide educators with new teaching methods "However, prior researches have focused on the impact of vocabulary size in reading comprehension while disregarding the role of vocabulary depth," according to [28]. He claims that the proportions of jargon profundity and understanding perception can be improved; nonetheless, it is unclear how much the expansiveness and profundity of jargon information aids perusing. 


\section{Research Methodology}

The current study used a quantitative research method integrating a correlation design to evaluate the relationship between reading comprehension and the amount of English authentic text vocabulary known by Afghan EFL earners. Correlation study studies the relationship between two or more variables and explains what exists between them [29]. The data were collected from the participants in this study utilizing the context questionnaire, the Reading Comprehension Test (RCT), and the Lexical Coverage Test (LCT) devised by [30]. The reading comprehension scores (dependent variable) and the amount of knowing vocabulary were the variables in this study (Independent variable). For numerous reasons, the quantitative correlational research approach was chosen. First, with 40 individuals, the sample size was bigger. Second, the quantitative method generates structured and numerical data [31] that the target audience can understand with few explanations.

\section{Sampling}

A total of 40 Afghan EFL students from Kunduz University were selected to take part in two individual examinations as part of this study. At Kunduz University, these students are currently enrolled in key courses like as reading, writing, listening, speaking, and phonology. The study's participants were chosen using a convenience sampling method. It's worth noting that, at the time of this study, the security situation was dire due to a conflict between competing political organizationsAfghan EFL students and other students were only occasionally available to take part in the study. Most Afghan students, particularly girls, stayed at home to save their lives, and just a tiny number of participants continued their university education. There were 40 participants in total, with 30 men and 10 women. The fact that only 10 females participated in this study is due to the fact that most female students do not finish their university education due to family and cultural constraints. As a result, there were very few female students at the university where this research was done. Participants ranged in age from 17 to 24, with an average age of 20. All of the participants were native speakers of Pashto, Dari, and Uzbek, and a handful of them spoke at least one other language outside English.

\section{Research Instruments}

The data were gathered using three tools: a context questionnaire, a Reading Comprehension Test (RCT), and a Lexical Coverage Test (LCT). The first tool was a brief survey questionnaire that was delivered to respondents at Kunduz University in Kunduz, Afghanistan, in order to collect demographic information. Gender, age, native language, and foreign language experiences were all variables on the questionnaire. It also included data on the amount of time spent learning any foreign languages. The Reading Comprehension Test is the second instrument ( RCT). The tool was a real-life reading passage that was used to see how well the participants understood the real-life content. The Lexical Coverage Test is the third instrument (LCT). The vocabulary that participants highlighted as unknown words throughout the reading comprehension exam was used to create this application. The following paragraphs go over each of the tools mentioned above in detail.

\section{Testing Techniques}

The assessment methods employed in this study were adapted from Laufer and Sim (1985), who investigated EFL learners' reading comprehension and vocabulary knowledge.

\section{Context Questionnaire}

The first tool was a brief survey questionnaire that was delivered to EFL learners at Kunduz University in Kunduz, Afghanistan, in order to collect demographic information. The survey includes questions about the participants' gender, age, native language, and foreign language experiences. It also included data on the amount of time spent learning any foreign languages. Reading Comprehension Test (RCT)

A section of roughly 170 words was acquired for this study from the website afghan.asianews.com. The website usually publishes Afghan-related political, social, and other important news. The material was chosen based on the reading subject's final exam scores, which represent the pupils' proficiency level. This was done for two major goals: first, to measure the students' level of preparation; and second, to determine the students' level of motivation (e.g. pre-intermediate, intermediate, upper-intermediate). Second, because the data should be in line with the learners' level, the study should yield a satisfying result. The text, which was written about the role of Afghan female police, was written at a level suitable for pre-intermediate students. The topic (The role of Afghan female police) was chosen to encourage attendees to read the text thoroughly, eagerly, and respond to the five follow-up questions. As in Afghanistan employment of female police officer is a new duty, the topic is hot potato among Afghan EFL learners. The English authentic text with five follow-up open-ended questions was delivered to the attendees. This required participants to answer the five open-ended questions accordingly. The five open-ended questions were written in English, and the participants were required to respond in English. The major purpose, however, was to assess their comprehension of the material rather than their grasp of the questions. The test had a total score of 20 points, with four points assigned to each question. To avoid mistakes, marks were double-checked 
by another evaluator to confirm the authenticity of the grading. There were no significant discrepancies between the first and second instances of checking, according to the results of the second check. When using such method in the research, it is clear that 20 out of 20 marks indicates highest understanding. If 5 marks disregard because of human error, 15 out of 20 marks, or $75 \%$, will suffice.

\section{Lexical Coverage Test (LCT)}

The term "lexical coverage test" represents the number of words in the English authentic text that are understood (Adolphs \& Schmitt, 2003). Partakers in the study were then given the LCT connected to the text based on the vocabularies they had already highlighted after highlighting the unfamiliar words in the paragraph. This covered all of the terms underlined by participants in the earlier session, and participants were instructed to write or paraphrase the meaning of the highlighted words. The researcher does this to see if the participants actually do not understand the meanings of the highlighted language. It's worth noting that participants can translate the words into Pashto or Dari, depending on their native tongue. The major goal of this test was to determine how many terms each participant knew and to prevent participants from making unintended mistakes during the test. Furthermore, the test's goal was to determine which words were correctly translated, incorrectly translated, misconstrued, and accurately interpreted. The researcher needs to know whether the attendees truly do not know the words they underlined in the previous exam, therefore the average objective of translating vocabulary is to ensure the validity of the lexical coverage test.

\section{Findings and Discussions}

The study's goal is to look at the relationship between reading comprehension and vocabulary knowledge in actual English texts among Afghan EFL students. The findings and discussion of the study are described in this section, which is based on the following research questions:

\section{Does degree of reading comprehension and amount of vocabulary knowledge relate with each other in English authentic texts among Afghan EFL learners significantly?}

The researcher looks at the respondents' reading comprehension scores first, then the lexical coverage test results, before looking at the link between variables. As previously stated, a paragraph of approximately 170 words was obtained from the afghan.asianews.com website and provided to the participants for the purpose of measuring their reading comprehension ability. Reading Comprehension Test is the name of this phase of data collection (RCT). Participants in the study were instructed to read the original text and underline any unfamiliar words. The participants were asked to answer the five follow-up questions after reading the authentic text and highlighting the unknown terms. As the stage came to a close, the contestants were given the following scores.

Figure 1 shows that seven participants (20\%) obtained a score of 20 out of 20 ; twenty-three participants $(57 \%)$ received a score of 15 or higher, and only ten participants $(25 \%)$ received a score of less than 15 . As previously stated, any participant who achieves a score of 15 or higher demonstrates acceptable comprehension of the reading text. Finally, it was discovered that the majority of the participants $(75 \%)$ had a good understanding of the text. The students' results could be attributable to the participants' familiarity with the passage's huge number of words. In line with this, Boyer (2017) discovered that the more the number of terms a reader knows, the better their comprehension is. 


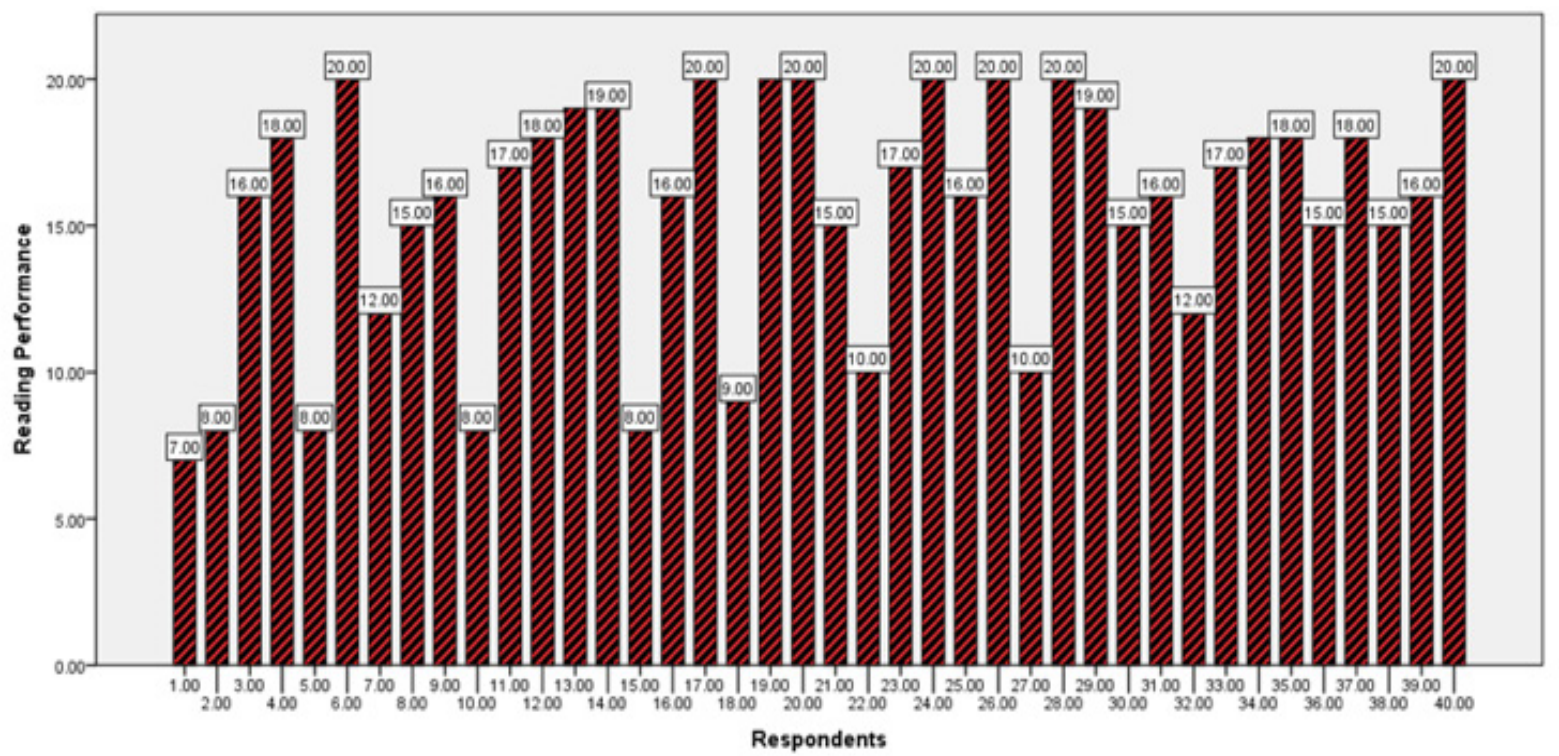

Figure 1. Reading Comprehension Scores

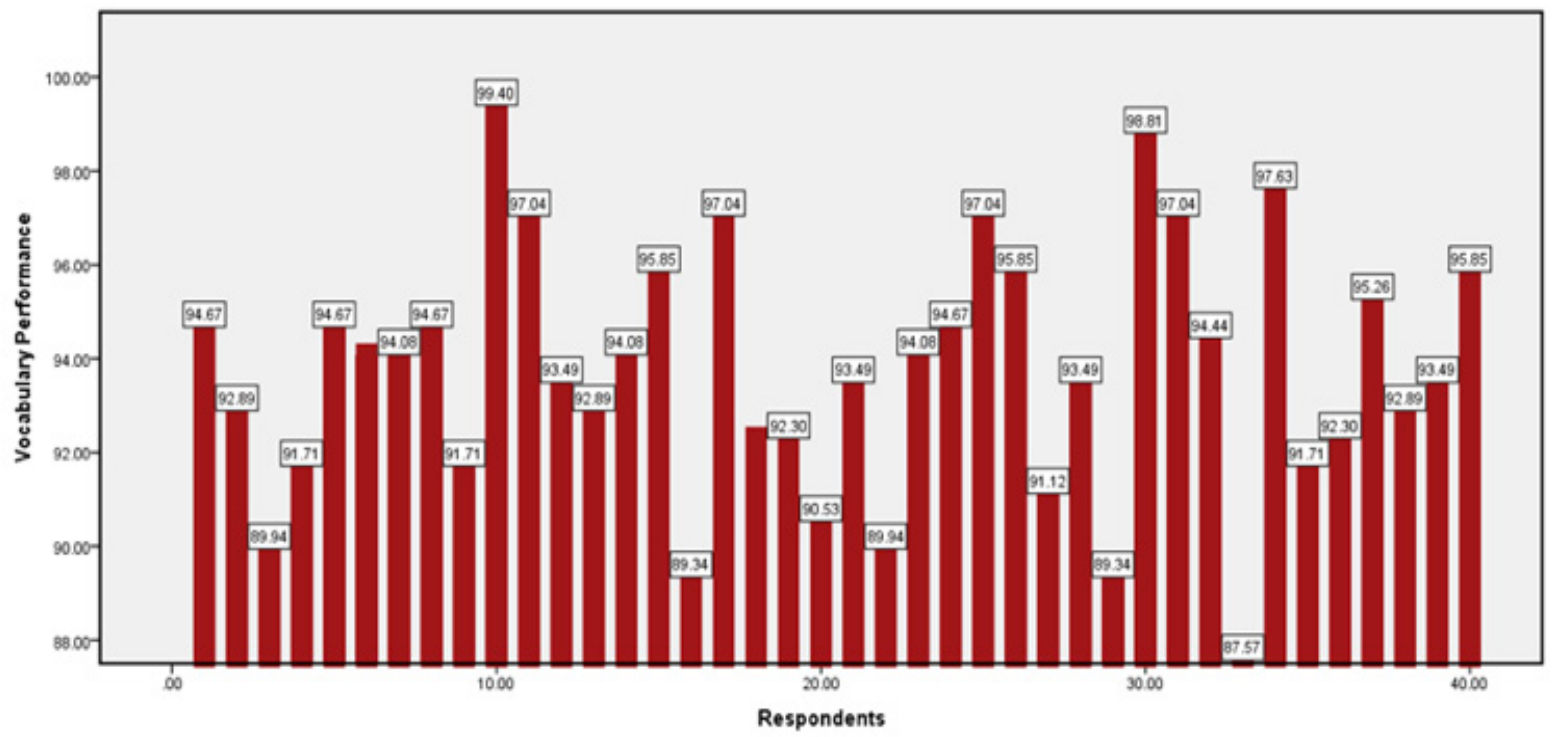

Figure 2. Vocabulary Knowledge Scores

As indicated in Figure 2, 20 participants (50\%) comprehended terms with a lexical coverage of 94 percent or higher in the presented paragraph, whereas 37 participants $(92.5 \%)$ understood words with a lexical coverage of 90 percent to 94 percent. Only three people $(7.5 \%)$ achieved less than 90 percent on the lexical coverage test while reading passages. The majority of participants were presumed to have an adequate understanding of the passage's terminology. Moreover, according to Masrai and Milton (2012), students must be familiar with 8000-9000 word families to comprehend authentic literature, but some technical and academic publications may require a higher number of words to comprehend.

\section{Hypothesis Test}

The following are the hypotheses that will be tested to see if there is a link between reading comprehension assessments and the proportion of vocabulary learned by EFL students.

Ho: Degree of reading comprehension and amount of vocabulary knowledge does not relate with each other in English authentic texts significantly.

Degree of reading comprehension and amount of vocabulary knowledge relates with each other in English text among Afghan EFL learners. 
Table 1. Correlation between Reading Comprehension and Percentage of Known Vocabulary

\begin{tabular}{|c|c|c|c|}
\hline & & $\begin{array}{c}\text { RCT } \\
\text { Scores }\end{array}$ & $\begin{array}{c}\text { Percentage of } \\
\text { Known Words }\end{array}$ \\
\hline \multirow{3}{*}{$\begin{array}{l}\text { Percentage } \\
\text { of Known } \\
\text { Words }\end{array}$} & $\begin{array}{c}\text { Pearson } \\
\text { Correlation }\end{array}$ & $.910^{* *}$ & 1 \\
\hline & $\begin{array}{c}\text { Sig. } \\
\text { (2-tailed) }\end{array}$ & .000 & \\
\hline & $\mathrm{N}$ & 40 & 40 \\
\hline \multirow{3}{*}{ RCT Scores } & $\begin{array}{c}\text { Pearson } \\
\text { Correlation }\end{array}$ & 1 & $.910^{* *}$ \\
\hline & $\begin{array}{c}\text { Sig. } \\
\text { (2-tailed) }\end{array}$ & & .000 \\
\hline & $\mathrm{N}$ & 40 & 40 \\
\hline
\end{tabular}

The Pearson Rho Correlation Test was performed to check if the degree of reading comprehension and vocabulary knowledge substantially connected with each other in English authentic text, and the results of each participant's exams were evaluated using SPSS. The Pearson Rho Correlation test found a significant positive correlation between the above-mentioned variables. Table 1 revealed a significant relationship between the dependent variable (reading comprehension scores) and the independent variable in the authentic reading passage ( percent of known terms). There is a strong association between reading comprehension scores and the percentage of known terms, according to the statistical analysis of the reading passage on the topic of (Female Police Responsibility). Finally, in SPSS, the value of Pearson's $r$ ranges from +1 to -1 , with +1 denoting a perfect positive correlation and -1 denoting a perfect negative correlation. Furthermore, if the $\mathrm{r}$ value is zero, there is no relationship. As a result, in table 4.1, the Pearson's $\mathrm{r}$ value is $=.910$, which is close to +1 , and the P-value is significantly less than 0.05, which is P.000. Based on the foregoing statistical analysis, the null hypothesis is rejected, and the dependent variable (reading comprehension scores) and the independent variable have a high correlation (percentage of known words). A statistics report for a correlation table is $\mathrm{r}=.910, \mathrm{n}=40, \mathrm{p}=.000$. Previous research has demonstrated a strong link between students' reading comprehension and vocabulary knowledge (Zhang \& Zhang, 2020; Qian, 2002; Koda, 1989). Previous studies have suggested doing a pre- and post-test during the reading process to examine if there is a link between levels of vocabulary knowledge and the amount of time spent reading.

\section{Conclusions}

The purpose of this study is to see how reading comprehension and vocabulary knowledge are related in genuine English texts among Afghan EFL students. According to the findings, there is a strong link between reading comprehension and vocabulary knowledge. To put it another way, the goal of this study is to see how reading comprehension and vocabulary knowledge relate in real-life English texts among Afghan EFL students. It is discovered that reading comprehension and vocabulary knowledge have a close link. To put it another way, the reading comprehension of Afghan EFL students was highly linked to their vocabulary knowledge. There are a few limitations to this study that preclude the results from being applied to all Afghan EFL students. The study's first weakness was the use of a limited sample size of only 40 individuals, which cannot be applied to the broader population. The use of a single instrument that exclusively focused on quantitative data was the study's second shortcoming. The study's third flaw was its narrow reach, which was limited to university EFL students. Due to the small number of participants and lack of gender equality in this study, more research is needed to include a large sample size of male and female respondents in order to further generalize the results to a larger sample size. Furthermore, future study should triangulate data using more than two instruments in order to acquire more trustworthy and in-depth information from participants. It is also advised that a comparable study be conducted in multiple settings, including both university and school EFL students, to see if EFL students' reading comprehension and vocabulary knowledge are linked. The ability of students to comprehend what they read was highly linked to their vocabulary knowledge.

\section{REFERENCES}

[1] Oxford, R. (2001). Integrated skills in the ESL/EFL classroom. ESL Magazine, 4(1), 18-20.

[2] Katawazai, R., Haidari, M. and Sandaran, S. C. (2019) 'An evaluation of sub-skills (vocabulary, grammar and pronunciation) in the grade 9 English textbook of Afghan secondary schools', International Journal of Engineering and Advanced Technology, 8(5), pp. 1236-1241.

[3] Gu, T. (2017). The effect of vocabulary knowledge on Chinese English learners' reading comprehension. International Journal of English Linguistics, 7(4), 45-55.

[4] Matsuoka, W., \& Hirsh, D. (2010). Vocabulary Learning through Reading: Does an ELT Course Book Provide Good Opportunities?. Reading in a foreign language, 22(1), 56-70.

[5] Alharthi, T. (2018). Minding the gap in vocabulary knowledge: Incidental focus on collocation through reading. Arab World English Journal, 9(2), 3-22. https://doi.org/10.24093/awej/vo19no2.1.

[6] Alqahtani, M. (2015). The importance of vocabulary in language learning and how to be taught. International Journal of Teaching and Education, 3(3), 21-34.

[7] Kacani, L., \& Cyfeku, J. (2015). Developing EFL Vocabulary through Speaking and Listening Activities. Academic Journal of Interdisciplinary Studies, 4(3 S1), 390-390. 
[8] Nation, I. S. P. (2005). Teaching and learning vocabulary. In Handbook of research in second language teaching and learning (pp. 605-620). Routledge.

[9] Tocaimaza-Hatch, C. C. (2018). Speaking is doing and doing is learning: vocabulary learning in service-learning. Journal of Spanish Language Teaching, 5(1), 66-80.

[10] Karlsson, P. and Mansory, A. (2007) 'An Afghan dilemma: Education, gender and globalisation in an Islamic context'. Pedagogiska institutionen.

[11] Cunningham, A. E., \& Stanovich, K. E. (1998). What reading does for the mind. American educator, 22, 8-17.

[12] Coady, J. (1997). L2 vocabulary acquisition through extensive reading.

[13] Schmitt, N. (2010). Researching vocabulary. Nottiingham, Nottingham: University of Nottingham.

[14] Afflerbach, P., Pearson, P. D., \& Paris, S. G. (2008). Clarifying differences between reading skills and reading strategies. The Reading Teacher, 61(5), 364-373.

[15] Mikulecky, B. S., \& Jeffries, L. (1996). Reading power: Reading for pleasure, comprehension skills, thinking skills, reading faster. Reading, Mass: Addison-Wesley,.

[16] Jose, G. R. (2015). Acquisition of Vocabulary by Dint of Unique Strategies: Indispensible for Fostering English Language Skills. Journal on English Language Teaching, 5(2), 7-18

[17] Vidal, K. (2003). Academic listening: A source of vocabulary acquisition?. Applied Linguistics, 24(1), 56-89.

[18] Nation, I. S. P. (2001). Learning vocabulary in another language. UK. Cambridge University Press

[19] Stahl, S. A. (2003). Vocabulary and readability: How knowing word meanings affects comprehension. Topics in language disorders, 23(3), 241-247.

[20] Laufer, B. (1992). How much lexis is necessary for reading comprehension?. In Vocabulary and Applied Linguistics (pp. 126-132). Palgrave Macmillan, London.
[21] Nxumalo, M. W. (2016). Relationships between reading ability, vocabulary, reading attitudes and academic perfomance among form 5 learners in Swaziland's public schools (Doctoral dissertation).

[22] Masrai, A., Milton, J. (2012). The vocabulary knowledge of university students in Saudi Arabia. Perspectives TESOL Arabia, 19(3), 13-19

[23] Boyer, K. (2017). The relationship between vocabulary and reading comprehension in third grade students who are English language learners and reading below grade level.

[24] Chou, P. T. M. (2011). The effects of vocabulary knowledge and background knowledge on reading comprehension of Taiwanese EFL students. Electronic Journal of Foreign Language Teaching, 8(1).

[25] Choi, H. Y. (2013). Effects of depth and breadth of vocabulary knowledge on English reading comprehension among Korean high school students.

[26] Martin - Chang, S. L., \& Gould, O. N. (2008). Revisiting print exposure: Exploring differential links to vocabulary, comprehension and reading rate. Journal of Research in Reading, 31(3), 273-284.

[27] $\mathrm{Gu}, \mathrm{T}$. (2017). The effect of vocabulary knowledge on Chinese English learners' reading comprehension. International Journal of English Linguistics, 7(4), 45-55.

[28] Porter, S., \& Carter, D. E. (2000). Common terms and concepts in research. The research process in nursing, 4, $17-28$

[29] Laufer, B., \& Sim, D. D. (1985). Measuring and explaining the reading threshold needed for English for academic purposes texts. Foreign language annals, 18(5), 405-411.

[30] Tracy, S.J. (2013) Qualitative research methods. Wiley-Black Well, West Sussex.

[31] Zahar, R., Cobb, T., \& Spada, N. (2001). Acquiring vocabulary through reading: Effects of frequency and contextual richness. Canadian Modern Language Review, 57(4), 541-572. 